\title{
Milk fatty acids as possible biomarkers to diagnose hyperketonemia in early lactation
}

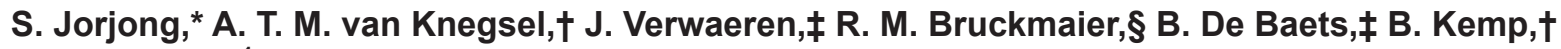 \\ and V. Fievez ${ }^{* 1}$ \\ *Laboratory for Animal Nutrition and Animal Product Quality, Ghent University, Proefhoevestraat 10, 9090 Melle, Belgium \\ †Adaptation Physiology Group, Department of Animal Science, Wageningen University, PO Box 338, 6700 AH Wageningen, the Netherlands \\ ‡KERMIT, Department of Mathematical Modelling, Statistics and Bioinformatics, Ghent University, Coupure links 653,9000 Ghent, Belgium \\ $\S$ Veterinary Physiology, Vetsuisse Faculty, University of Bern, Bremgartenstrasse 109a, $\mathrm{CH}-3001$ Bern, Switzerland
}

\section{ABSTRACT}

The aim of this study was to assess the potential of milk fatty acids as diagnostic tool for hyperketonemia of 93 dairy cows in a $3 \times 2$ factorial arrangement. Cows were fed a glucogenic or lipogenic diet and originally were intended to be subjected to a 0-, 30-, or 60-d dry period. Nevertheless, some of the cows, which were intended for inclusion in the 0-d dry period group, dried off spontaneously. Milk was collected in wk 2, 3, 4, and 8 of lactation for milk fat analysis. Blood was sampled from wk 2 to 8 after parturition for $\beta$-hydroxybutyrate (BHBA) analysis. Cases were classified into 2 groups: hyperketonemia (BHBA $\geq 1.2 \mathrm{mmol} / \mathrm{L}$ ) and nonhyperketonemia (BHBA $<1.2 \mathrm{mmol} / \mathrm{L}$ ). Concentrations of 45 milk fatty acids and ratios of anteiso C15:0-toanteiso $\mathrm{C} 17: 0$ and $\mathrm{C} 18: 1$ cis-9-to-C15:0 were subjected to a logistic regression analysis (stepwise forward method). The milk fat $\mathrm{C} 18: 1$ cis-9-to-C15:0 ratio revealed the most discriminating factor for diagnosis of hyperketonemia. Ninety percent of nonhyperketonemia cases showed a milk fat $\mathrm{C} 18: 1$ cis-9-to-C15:0 ratio of 40 or lower, whereas $70 \%$ of cows suffering from hyperketonemia showed milk fat C18:1 cis-9-to-C15:0 ratios exceeding 40. Additionally, cows with a milk fat ratio C18:1 cis-9-to-C15:0 of at least 45 in wk 2 after parturition had about $50 \%$ chance to encounter blood plasma BHBA values of $1.2 \mathrm{mmol} / \mathrm{L}$ or more during the first 8 wk of lactation. Of the cows not suffering from hyperketonemia during the first 2 mo of lactation, only $9 \%$ exceeded this wk 2 threshold. Practical implementation requires routine analysis of both milk fatty acids, which currently is lacking for C15:0. The inclusion of other variables, such as test-day information and a more frequent sampling protocol should be

Received August 11, 2014.

Accepted April 27, 2015.

${ }^{1}$ Corresponding author: veerle.fievez@ugent.be considered to further improve diagnostic performance of this biomarker.

Key words: biomarker, hyperketonemia, milk fatty acid

\section{INTRODUCTION}

Negative energy balance is a common phenomenon in the transition period in dairy cows. During this period, increase in feed intake is lagging behind increasing energy demand for milk production, which results in an often-serious energy imbalance. Mainly the supply of glucogenic precursors, in particular the ruminal production of propionic acid, is often insufficient (Heuer et al., 2000). As a result, blood glucose and insulin concentrations are low and body fat is mobilized and transported as NEFA to several organs, particularly to the liver in which these FA are oxidized to produce energy. Due to the limited availability of propionate, however, complete oxidation of NEFA is impaired, resulting in the production of ketone bodies (BHBA, acetoacetate, and acetone), which might be referred to as hyperketonemia (Herdt, 2000). Hyperketonemia or subclinical ketosis $(\mathbf{S C K})$ is defined when the concentration of blood BHBA is above the threshold of 1.2 to 1.4 $\mathrm{mmol} / \mathrm{L}$, and is considered a critical metabolic disorder in dairy cows (Duffield et al., 2009). Hyperketonemia is detrimental to the cow's health and production [e.g., BHBA concentrations exceeding thresholds of 1.1 or $1.6 \mathrm{mmol} / \mathrm{L}$ during the first $2 \mathrm{wk}$ postpartum were associated with a diminished probability of pregnancy (Walsh et al., 2007; Roberts et al., 2012)]. Moreover, milk losses of 1.5 to $2.4 \mathrm{~kg} / \mathrm{d}$ were linked with BHBA in wk 2 and 1 after calving, exceeding thresholds of 1.2 and $1.4 \mathrm{mmol} / \mathrm{L}$, respectively (Chapinal et al., 2012). Similarly, Duffield et al. (2009) indicated that blood BHBA above $1.4 \mathrm{mmol} / \mathrm{L}$ in the first 2 wk postpartum increased disease risk and resulted in substantial milk yield losses in early lactation $(-1.88 \mathrm{~kg} / \mathrm{d})$. Moreover, in the study of McArt et al. (2012) in the first $30 \mathrm{~d}$ in 
milk, cows with SCK were 19.3 times more likely to develop displaced abomasum, and 3 times more likely to die or be culled than nonketotic cows.

Excessive amounts of NEFA released during body fat mobilization are transferred to the milk. Because these NEFA are particularly rich in long-chain FA such as C18:1 cis-9 and C18:0 (Hostens et al., 2012), elevated concentrations in milk fat of those FA were identified as valuable early warning biomarkers for SCK (Van Haelst et al., 2008). These findings, however, were based on a limited data set. Moreover, excessive mobilization of body reserves will not result in the development of SCK when sufficient glucogenic precursors are available in the liver (Rukkwamsuk et al., 1999). Hence, besides a biomarker in milk for body fat mobilization, a biomarker for energy status might be required to accurately assess the cow's risk for hyperketonemia. Milk FA that could provide additional information on the cow's glucose status are odd-chain FA that are positively related to propionate (e.g., C15:0 and C17:0) as they are de novo synthesized either by bacteria in the rumen or in the udder with propionate as the main precursor (Fievez et al., 2012).

Therefore, this study is a first attempt to assess the potential for milk FA as biomarkers for hyperketonemia. For this, milk and blood plasma sampled during the first 8 wk after parturition were used. Samples were obtained from 93 lactating cows receiving either a glucogenic or a lipogenic diet in early lactation after a normal $(60 \mathrm{~d})$ or shortened (30 d) dry period or without dry period in a $3 \times 2$ factorial arrangement. The objective was approached in 3 steps: (1) measurement of FA profiles (i.e., 45 milk FA and 2 milk fat ratios) in milk and BHBA in blood plasma, (2) logistic regression to determine the milk FA with the greatest biomarker potential, and (3) assessment of the potential value of these milk FA as diagnostic biomarkers as well as a predictor of future cases of hyperketonemia.

\section{MATERIALS AND METHODS}

\section{Experimental Setup, Animals, and Housing}

Samples and data for the current study were obtained from an experiment where dairy cows were attributed to different dry period lengths and diets and monitored for 2 successive lactations. The current study involved samples and data from the second lactation. The experimental design for the second lactation was similar to the first lactation (Jorjong et al., 2014; van Knegsel et al., 2014) with some exceptions as specified below.

The Institutional Animal Care and Use Committee of Wageningen University and Research Center approved the experimental protocol. The experimental setup and diet composition were presented earlier (van Knegsel et al., 2014). In short, Holstein-Friesian dairy cows (n $=108$ ) were selected from the Dairy Campus Research dairy herd (WUR Livestock Research, Lelystad, the Netherlands) for $3 \times 2$ experiment on the effect of dry period length $(0,30$, and $60 \mathrm{~d})$ and transition diet (glucogenic or lipogenic) on energy balance and metabolic health (assessed by plasma BHBA). Cows were blocked for parity (primiparous or multiparous). Moreover, cows were allocated to the 6 treatment groups to equally stratify all groups for following parameters: expected calving date, milk production in the previous lactation, and BCS.

Cows were housed in a freestall with slatted floor and cubicles. During lactation, cows were milked twice daily $(0500$ and $1630 \mathrm{~h})$. The drying-off protocol for cows with the 30- and 60-d dry period consisted of a transition to the far-off ration at $\mathrm{d} 7$ before drying off, and milking once daily from d 4 before drying off. At drying off, cows were treated with an intramammary antibiotic (Supermastidol, Virbac Animal Health, Barneveld, the Netherlands). Milk yield was recorded daily. Dry cows received a dry cow ration, which was composed of grass silage, corn silage, soybean meal, rapeseed meal, and rapeseed straw or wheat straw in a ratio of 39:25:4:8:25 (DM basis). Prepartum lactating cows received a lactating cow ration supporting $25 \mathrm{~kg}$ of milk. From d 10 before the expected calving and onward, cows of all treatments were fed $1 \mathrm{~kg} / \mathrm{d}$ glucogenic or lipogenic concentrate, which was increased stepwise postcalving with $0.5 \mathrm{~kg} / \mathrm{d}$ until the concentrate supply reached 8.5 $\mathrm{kg} / \mathrm{d}$. The glucogenic concentrate specifically contained more corn, which was largely replaced by sugar beet pulp, palm kernel, and rumen-protected palm oil in the lipogenic concentrate. Forage was supplied ad libitum and was composed of grass silage, corn silage, straw (wheat straw or rapeseed straw), and a protein source (rapeseed meal or soybean meal) in a ratio of 50:34:4:11 (DM basis). Diets were formulated to be isocaloric (net energy basis; VEM system; Van Es, 1975) and equal in intestinal digestible protein and degraded protein balance (Tamminga et al., 1994). Details of the chemical composition of the diets were presented by Jorjong et al. (2014) and van Knegsel et al. (2014). Treatments were planned to be imposed on cows for 2 successive lactations. During or after the first lactation, some cows left the experiment for different reasons (mainly failure to become pregnant). Furthermore, at least $30 \mathrm{~d}$ before the second lactation, milk production of part of the cows $(\mathrm{n}=15)$ within the 0 -d dry period group in the first lactation was below $4 \mathrm{~kg} / \mathrm{d}$. We decided to give these cows a dry period as, essentially, they spontane- 
ously dried off. The drying-off protocol for these cows consisted of a transition to the far-off ration, but they were not treated with an intramammary antibiotic. Hence, the dry period treatment in the second lactation in practice consisted of 4 classes $(0,0 \rightarrow 30,30$, or $60 \mathrm{~d})$.

Blood samples were taken weekly from wk 3 precalving until wk 8 postcalving. Blood was sampled from the coccygeal vessel into evacuated tubes (Vacuette, Greiner BioOne, Kremsmunster, Austria) containing EDTA. Blood plasma was obtained by centrifugation for $10 \mathrm{~min}$ at $2,900 \times \mathrm{g}$ at $4^{\circ} \mathrm{C}$. Blood plasma samples were kept at $-20^{\circ} \mathrm{C}$ until analysis for plasma metabolites. Milk sampling for FA analysis took place every Friday morning in wk 2, 3, 4, and 8 postcalving. Milk samples were collected in $10-\mathrm{mL}$ tubes and were stored at $-20^{\circ} \mathrm{C}$. Frozen milk samples were sent to the Laboratory for Animal Nutrition and Animal Product Quality (Faculty of Bioscience Engineering, Ghent University, Belgium). From the 108 cows, 15 cows were excluded because data were incomplete (missing milk FA of wk 2, 3, 4, and 8; blood plasma BHBA from wk 2 to 8 of lactation; or both). Hence, only 93 cows were used in the data analysis. The health status of the cows was checked regularly by the animal care personnel, and animals were treated for diseases if required. Details on the incidence of clinical ketosis and other diseases (i.e., endometritis and retained placenta/uterine infections are included in the Results section).

\section{Milk Analysis}

The FA profile was obtained after milk fat extraction (mini Röse-Göttlieb method, adapted from Chouinard et al. (1997), methylation (Stefanov et al., 2010), and gas chromatographic analysis of FAME (Agilent Technologies 7890A GC System equipped with a flame ionization detector, Agilent Technologies, Santa Clara, CA). Samples were injected by split injection (split ratio 1:50). The carrier gas was hydrogen, with an inlet pressure $246.38 \mathrm{kPa}$. Fatty acid peaks were identified based on their retention times. Separation of FAME was realized with a Supelco column (SP-2560, Sigma-Aldrich, Bellefonte, PA; $75 \mathrm{~m} \times 180 \mu \mathrm{m} \times 0.14$ $\mu \mathrm{m})$. The temperature program ran from a starting temperature of $70^{\circ} \mathrm{C}$ for $2 \mathrm{~min}$, increasing $15^{\circ} \mathrm{C} / \mathrm{min}$ to $150^{\circ} \mathrm{C}$; from 150 to $165^{\circ} \mathrm{C}$ by an increase of $1^{\circ} \mathrm{C} / \mathrm{min}$, then $165^{\circ} \mathrm{C}$ was held for $12 \mathrm{~min}$; from 165 to $170^{\circ} \mathrm{C}$ the temperature increased at $2^{\circ} \mathrm{C} / \mathrm{min}$, with $170^{\circ} \mathrm{C}$ held for $5 \mathrm{~min}$ and from 170 to $215^{\circ} \mathrm{C}$, an increase of $5^{\circ} \mathrm{C} / \mathrm{min}$ was applied, with the final temperature kept for 10 min. Fatty acid methyl esters were determined with Agilent ChemStation software (B.04.03; Agilent Technologies) and tridecanoic acid (C13:0; as triacyl- glyceride; Sigma, Bornem, Belgium) was used as an internal standard. Fatty acids were expressed as grams per $100 \mathrm{~g}$ of FAME. Fatty acid peaks were identified through mixtures of methyl ester standards (BR2 and BR3, Larodan Fine Chemicals AB, Malmö, Sweden; Supelco 37, Supelco Analytical, Bellefonte, PA; PUFA3, Matreya LLC, Pleasant Gap, PA) based on retention times. Short-chain FA were corrected for their respective theoretical relative response factors (Ackman and Sipos, 1964; Wolff et al., 1995).

\section{Blood Plasma Metabolites}

Concentration of plasma BHBA was measured enzymatically with a selective analyzer (Cobas Mira 2, Hoffmann-La Roche, Basel, Switzerland) by the Veterinary Physiology group (Veterinary Physiology, Vetsuisse Faculty, University of Bern, Bern, Switzerland) using commercial kit no. RB1007 from Randox Laboratories (Ibach, Switzerland), as described by Graber et al. (2012). The kinetic enzymatic method to measure the concentration of BHBA in plasma is based on the oxidation of BHBA to acetoacetate by the enzyme BHBA dehydrogenase. Concomitant with this oxidation, the cofactor $\mathrm{NAD}^{+}$is reduced to NADH and the associated change of absorbance is directly correlated with the BHBA concentration.

\section{Statistical Analysis, Calculations, and Generation of Functions}

Descriptive Statistics. The milk FA characteristic that was identified as the most discriminatory to classify hyperketonemia cases (i.e., C18:1 cis-9-to-C15:0 ratio, see further) as well as blood plasma BHBA were subjected to a repeated-measures ANOVA (ANOVA mixed model of SAS Enterprise Guide 5). Data were normalized before this analysis (natural logarithm transformation; SPSS 22.0, SPSS Inc., Chicago, IL). Lactation week was considered as the repeated effect (wk 2 to 8 for blood plasma BHBA and wk 2, 3, 4, and 8 for milk fat C18:1 cis-9-to-C15:0 ratio). Cow was defined as random effect. Dry period treatment $(0,0 \rightarrow 30,30$, or 60 d), diet (glucogenic or lipogenic), and their interaction terms were included in the model as fixed effects. In attempting to choose the best covariance structure, the Akaike information criterion was used to select the best model structure. A first-order autoregressive structure [AR(1)] was the best fit and was used to account for within-dry period $\times$ diet variation of BHBA, whereas a first-order heterogeneous structure was used to account for within-dry period $\times$ diet variation of milk fat C18:1 cis-9-to-C15:0 ratio. Furthermore, the relation between 
milk fat $\mathrm{C} 18: 1$ cis-9-to-C15:0 ratio and blood plasma BHBA was assessed through linear regression (SPSS 22.0).

BHBA Threshold Definition. Classification of the observation was based on blood plasma BHBA thresholds, where postpartum BHBA values greater than or equal to $1.2 \mathrm{mmol} / \mathrm{L}$ were classified as 1 , which stands for hyperketonemia (LeBlanc et al., 2005; van der Drift et al., 2012; McArt et al., 2013); cases with blood plasma BHBA values lower than $1.2 \mathrm{mmol} / \mathrm{L}$ were classified as 0 , indicating nonhyperketonemia.

Logistic Regression. The aim of this step is to find the most discriminatory milk FA characteristic to distinguish between hyperketonemia or not, based on the variable inclusion in the equation (stepwise forward method). The 45 milk FA, as well as the milk FA ratios anteiso C15:0-to-anteiso $\mathrm{C} 17: 0$ and $\mathrm{C} 18: 1$ cis-9-to$\mathrm{C} 15: 0$, were subjected to a logistic regression analysis performed by SPSS 22.0. The latter analysis was performed for all 4 wk separately (wk 2, 3, 4, and 8). Additionally, inclusion of the 2 ratios (anteiso C15:0-toanteiso $\mathrm{C} 17: 0$ and $\mathrm{C} 18: 1$ cis-9-to-C15:0) was based on expert knowledge as explained in the Discussion section. After this first exploratory logistic regression analysis, a second logistic regression analysis was run in which classification was based on a single milk FA characteristic (i.e., the variable that first entered in the former logistic regression). The logistic regression analysis was based on data of wk 2,3 , and 4 as the incidence of hyperketonemia in wk 8 was limited (see Results section) and no milk FA data were available for wk 1, 5, 6, and 7. The performance of both classification models (based either on all milk FA and ratios or on a single milk FA characteristic) were assessed through cross-validated logistic regression (10-fold cross-validation procedure in SPSS 22.0).

Empirical Cumulative Probability Distributions for Diagnosis of Hyperketonemia. Empirical cumulative probability distributions were generated, expressing the cumulative probability of the milk fat C18:1 cis-9-to-C15:0 ratio. In particular, the cumulative probability distribution of the milk fat C18:1 cis-9-to-C15:0 ratio in case of hyperketonemia and nonhyperketonemia, respectively, was considered and denoted $h 1$ and h2, respectively. Denoting the milk fat C18:1 cis-9-to-C15:0 ratio as $R$ (the random variable under study), the corresponding curves were constructed through a stepwise increase of the milk fat C18:1 cis-9-to-C15:0 ratio from the minimum to the maximum value observed in the study:

$\mathrm{h} 1(\mathrm{r})=\frac{(\text { no. of hyperketonemia cases for which } \mathrm{R} \leq \mathrm{r})}{(\text { total no. of hyperketonemia cases in the study) }}$, $\mathrm{h} 2(\mathrm{r})=\frac{(\text { no. of nonhyperketonemia cases for which } \mathrm{R} \leq \mathrm{r})}{(\text { total no. of nonhyperketonemia cases in the study) }}$.

Empirical Cumulative Probability Distributions for Prediction of Hyperketonemia During the First 8 Weeks in Lactation. In this study, prediction of hyperketonemia during the first $8 \mathrm{wk}$ in lactation was assessed. For this purpose, the milk fat C18:1 cis-9-to-C15:0 ratio was determined in wk 2 after parturition, whereas cows were classified based on blood plasma BHBA in wk 2 to 8 . For this classification, cows were considered suffering from hyperketonemia in early lactation when the maximum blood plasma BHBA concentration at any time in this 7 -wk period was greater than $1.2 \mathrm{mmol} / \mathrm{L}$. Empirical probability distributions were generated as described before, but now including milk FA data of wk 2 only and the 0 or 1 classification based on the maximum blood plasma BHBA concentration observed from wk 2 to 8 in lactation. The cumulative probability distribution of the milk fat C18:1 cis-9-to-C15:0 ratio in wk 2 of lactation in case of hyperketonemia and nonhyperketonemia in the first 8 wk in lactation, denoted $e 1$ and $e \mathscr{2}$, respectively. Denoting the milk fat C18:1 cis-9-to-C15:0 ratio in wk 2 as $R_{2}$ (the random variable under study), the corresponding curves were constructed through a stepwise increase of the milk fat C18:1 cis-9-to-C15:0 ratio from the minimum to the maximum value observed in the study:

$$
\mathrm{e} 1(\mathrm{r})=\frac{\begin{array}{c}
\text { (no. of hyperketonemia cows in first } 8 \mathrm{wk} \\
\text { in lactation for which } \left.R_{2} \leq \mathrm{r}\right)
\end{array}}{\text { in lactation })},
$$

$$
\mathrm{e} 2(\mathrm{r})=\frac{\text { in first } \left.8 \mathrm{wk} \text { in lactation for which } R_{2} \leq \mathrm{r}\right)}{(\text { total no. of nonhyperketonemia cows }},
$$

Logistic Curve Fitting. Further, a logistic curve was fitted to the empirical cumulative probability distributions performed by nonlinear regression (SPSS $22.0)$. This curve is described based on the slope $\left(\beta_{0}\right)$, the inflection point of the curve $\left(\beta_{1}\right)$ and the upper limit $\left(\beta_{2}\right)$, which here equals 1 :

$$
y=\frac{\beta_{2}}{1+\exp \left[-\beta_{0} \times\left(x-\beta_{1}\right)\right]} .
$$




\section{RESULTS}

\section{Classification Based on Blood Plasma BHBA Thresholds and Influence of Experimental Factors (Dietary and Dry Period Management)}

Of all 372 observations in wk 2, 3, 4, and 8 after parturition, $19.6 \%$ were classified as suffering from hyperketonemia. When considering animal as an observational unit as in the case of hyperketonemia prediction during the first $8 \mathrm{wk}$ in lactation $(\mathrm{n}=93), 41 \%(\mathrm{n}$ $=38$ ) of the animals were classified as suffering from hyperketonemia at any time during the first $8 \mathrm{wk}$ in lactation. Two-thirds of the hyperketonemia cows (n $=25$ ) exceeded the BHBA threshold in multiple weeks (Figure 1a). Nevertheless, cows with a single observation exceeding the BHBA threshold were not treated differently from cows having multiple observations because of too limited group sizes (Figure 1a). Additionally, 13 cows (with all of them belonging to the hyperketonemia group) were found to suffer from 1 of the 3 following diseases: clinical ketosis, endometritis, or retained placenta/uterine infections. Three cows (8\%) were diagnosed to suffer from clinical ketosis, $2(5 \%)$ had endometritis, and $8(21 \%)$ suffered from retained placenta/uterine infections. Details on the distribution of these cows within the treatment groups are given in Supplemental Table S1 (http://dx.doi.org/10.3168/ jds.2014-8728).

The risk for hyperketonemia decreased when progressing in lactation (26.9 to $6.5 \%$ from wk 2 to 8 of lactation), as blood plasma BHBA concentrations decreased with time $(P=0.001)$ (Figure 1b). Blood plasma BHBA was affected by dry period management $(P=0.041$; Figure 1b). Particularly, the subgroup that spontaneously dried off (group $0 \rightarrow 30$ ) showed increased levels of blood plasma BHBA. In addition, blood plasma BHBA was not affected by any of the interaction effects, but was affected by diet, with the glucogenic diet suppressing concentrations of this plasma metabolite (average BHBA over 8 wk: 0.86 vs. $1.12 \mathrm{mmol} / \mathrm{L} ; P=0.005$ for the glucogenic and lipogenic diet, respectively).

\section{Identification of Milk FA Predominantly Linked with Blood Plasma BHBA: Logistic Regression and Correlations}

Given the highest incidence of hyperketonemia during the first month of lactation, milk FA data from wk 2,3 , and 4 were used to identify the most powerful variable for diagnosis of hyperketonemia using a logistic regression analysis. Of the 45 milk $\mathrm{FA}$, and the ratios of anteiso C15:0-to-anteiso C17:0 and $\mathrm{C} 18: 1$ cis-9-toC15:0 used to perform the logistic regression, the milk a)

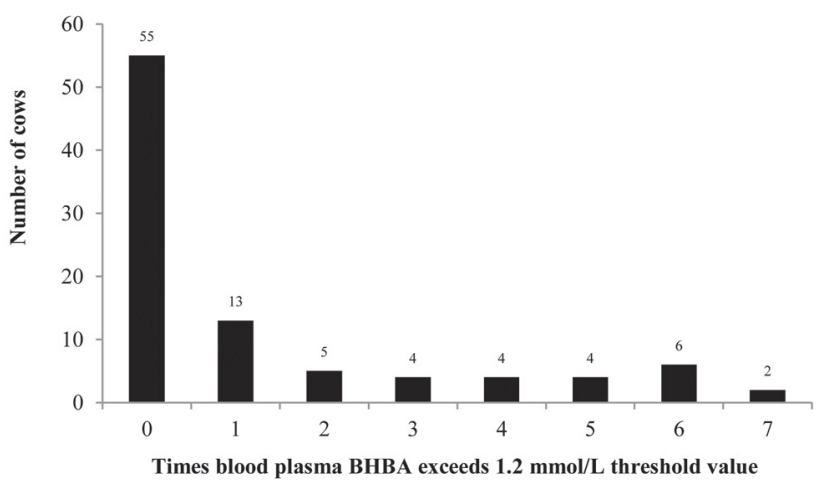

b)

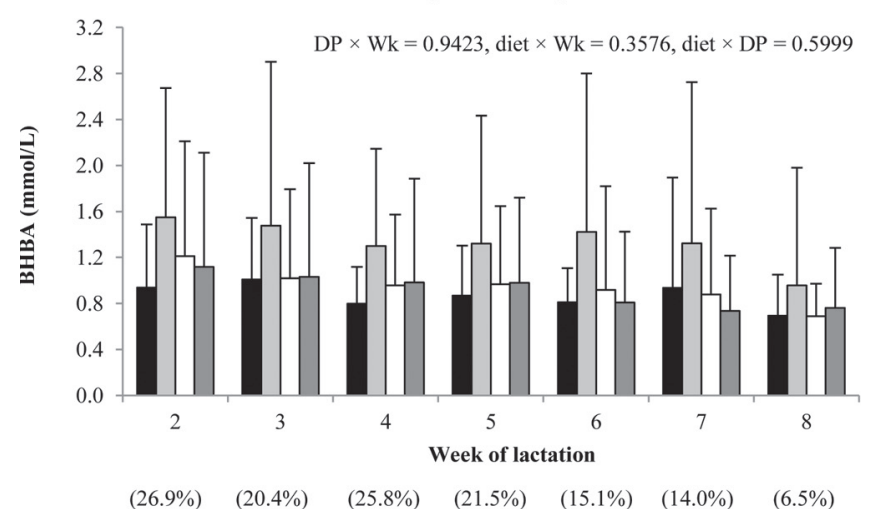

c)

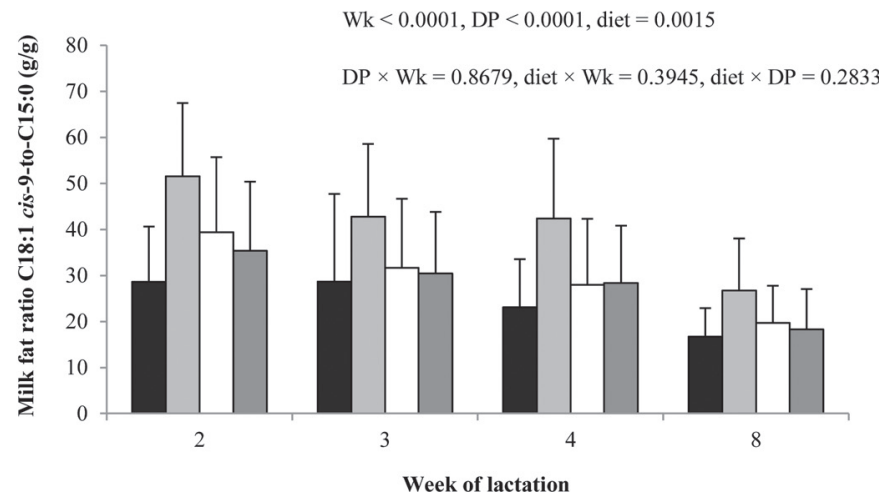

Figure 1. Number of cows with blood plasma BHBA concentrations not exceeding the threshold value of $1.2 \mathrm{mmol} / \mathrm{L}$ or exceeding the threshold once up to 7 times between 2 and 8 wk in lactation and based on a weekly sampling frequency (a). Blood plasma BHBA concentration and hyperketonemia incidence rates (in parentheses), as determined based on a weekly sampling frequency (b). Milk fat C18:1 cis-9-to-C15:0 ratio of dairy cows fed a glucogenic or lipogenic diet (diet) with dry period length of 0 (black bar), $0 \rightarrow 30$ (light gray bar), 30 (white bar), or $60 \mathrm{~d}$ (dark gray bar) during wk 2, 3, 4, and 8 of lactation (c). Values represent means per week; error bars present standard deviations; and $P$-values show main and interaction effects. 


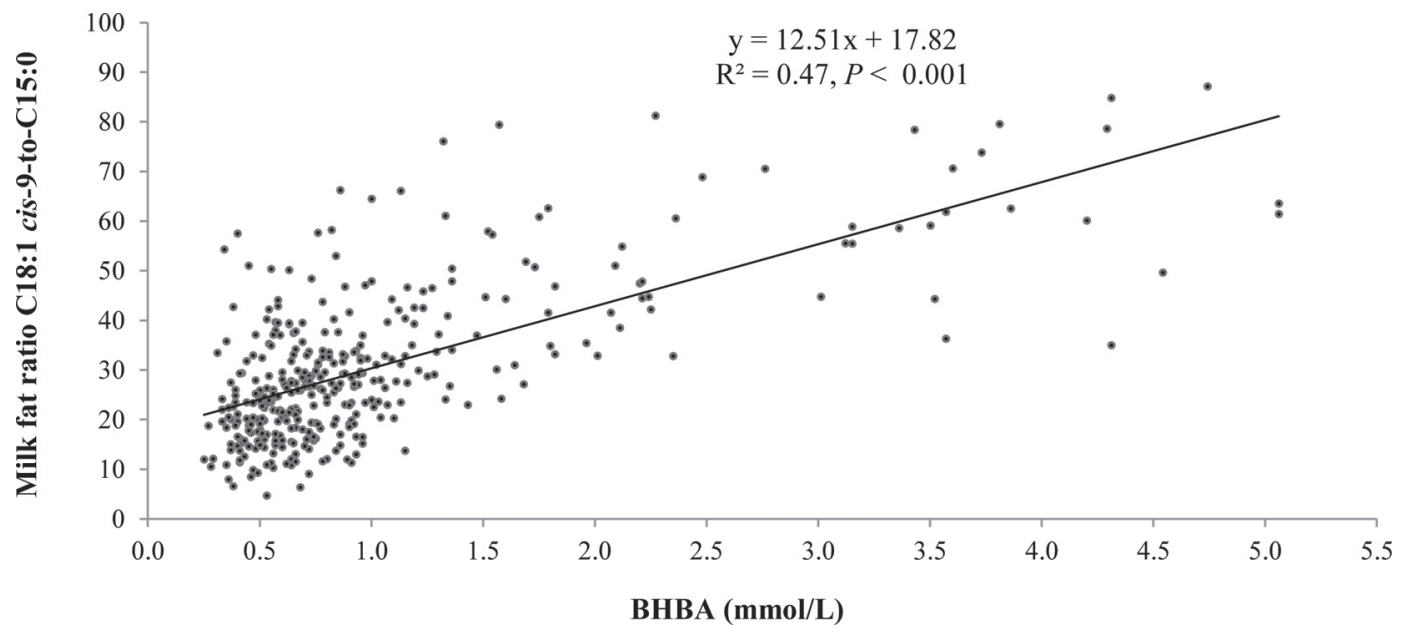

Figure 2. Correlation between blood plasma BHBA and milk fat ratio C18:1 cis-9-to-C15:0 of wk 2, 3, 4, and 8 of lactation $\left(\mathrm{n}=372 ; \mathrm{R}^{2}\right.$ $=0.47$ ).

fat C18:1 cis-9-to-C15:0 ratio was the first variable entered in the equation for classification of hyperketonemia cases (SPSS 22.0, SPSS Inc.). An overall classification accuracy of $87.3 \%$ was obtained based on 10 -fold cross-validation when grouping based on all milk FA variables and including observations of all weeks (wk 2, 3, 4, and 8). More specifically, 93.9 and $55.9 \%$ of the cases of the nonhyperketonemia group 0 (specificity) and hyperketonemia group 1 (sensitivity) were correctly classified, respectively. Ten-fold cross-validation based on the first variable entered in the logistic regression (i.e., the milk FA C18:1 cis-9-to-C15:0 ratio) showed the following performance: overall classification accuracy of $82.3 \%$, specificity of $95.0 \%$, and sensitivity of $38.4 \%$. Hence, overall classification accuracy based on $\mathrm{C} 18: 1$ cis-9-to-C15:0 only was somewhat lower as compared with classification based on the full variable set. A similar logistic regression was performed using milk C18:1 cis-9-to-C15:0 ratios of wk 2 to predict occurrence of hyperketonemia during any of the first $8 \mathrm{wk}$ in lactation. Ten-fold cross-validation showed an overall classification accuracy of $75.2 \%$, specificity of $78.5 \%$, and sensitivity of $75.3 \%$.

In accordance with blood plasma BHBA concentration, the milk fat $\mathrm{C} 18: 1$ cis-9-to-C15:0 ratio decreased with week in lactation $(P<0.001)$. This ratio was affected by dry period $(P<0.001)$ and $\operatorname{diet}(P=0.002)$. None of the interactions were significant (Figure 1c). Detailed information on the milk FA composition, in relation to the dry period length and glucogenic versus lipogenic ration is given in Supplemental Table S2 (http://dx.doi.org/10.3168/jds.2014-8728). The relation between milk fat $\mathrm{C} 18: 1$ cis-9-to-C15:0 ratio and blood plasma BHBA is further confirmed by the positive relation between both metabolites (Figure 2).
Nevertheless, the $\mathrm{R}^{2}$ value is relatively modest $(0.47$; $P<0.001$ ), indicating a limited potential for direct prediction of the blood plasma BHBA concentration from the milk fat $\mathrm{C} 18: 1$ cis-9-to-C15:0 ratio.

\section{Empirical Cumulative Probability Distributions for Diagnosis of Hyperketonemia}

The cumulative proportion of hyperketonemia cases to the total number of hyperketonemia cases observed in wk 2, 3, 4, and 8 was plotted against the milk fat $\mathrm{C} 18: 1$ cis-9-to-C15:0 ratio (ranging from 4.8 to 87.2 ) to which a logistic curve was fitted. This logistic curve is characterized by a parameter $\beta_{1}$, which equaled 49.1 , indicating that one-half of the hyperketonemia observations were associated with a milk fat C18:1 cis-9-to-C15:0 ratio of at least 49 (Figure 3). Similarly, a logistic curve was fitted for nonhyperketonemia observations, which allowed us to assess the false positive rate for each milk fat $\mathrm{C} 18: 1$ cis-9-to-C15:0 ratio. A milk fat $\mathrm{C} 18: 1$ cis9-to-C15:0 ratio above 40 was observed for $10 \%$ of the nonhyperketonemia cases (false positive rate). Interestingly, only $30 \%$ of the hyperketonemia cases were associated with milk fat C18:1 cis-9-to-C15:0 ratios below 40 (Figure 3). Similar curves were constructed for wk 2, 3 , and 4 separately (wk 8 was excluded due to the low hyperketonemia incidence rate). The logistic curve of the hyperketonemia cases is characterized by a parameter $\beta 1$, which decreased from wk 2 to wk 4 in lactation (54.4, 53.0, and 43.4, for wk 2, 3, and 4, respectively, Figure 4a). This indicates that the threshold of the milk fat C18:1 cis-9-to-C15:0 ratio, which half of the hyperketonemia observations exceeded, decreased with time after parturition. Similarly, a logistic curve was fitted for nonhyperketonemia observations, which in- 


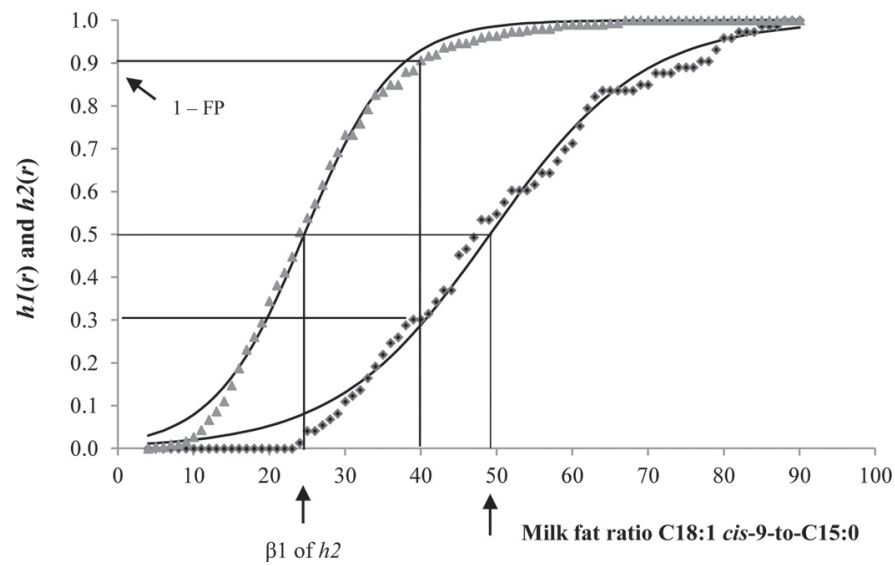

Figure 3. A logistic curve, $h 1$, representing the cumulative probability distribution of hyperketonemia cases (BHBA $\geq 1.2 \mathrm{mmol} / \mathrm{L}$ ) showing a milk fat $\mathrm{C} 18: 1$ cis-9-to-C15:0 ratio $(R) \leq r$ (black diamonds) to the combined number of hyperketonemia cases from wk 2 , 3,4 , and 8 of lactation. The logistic curve is characterized by its slope $\left(\beta_{0}=0.10\right)$ and inflection point $\left(\beta_{1}=49.1\right)$. Similarly, nonhyperketonemia cases proportional to the total number of nonhyperketonemia cases (h2) were presented in relation to $(R) \leq r$ (gray triangles), with $\beta_{0}$ and $\beta_{1}$ of 0.17 and 24.6 , respectively, presented as $1-\mathrm{FP}$ (false positive rate).

dicated $10 \%$ of the nonhyperketonemia cases exceeded milk fat C18:1 cis-9-to-C15:0 ratios of 45, 38, and 35 in wk 2,3 , and 4 , respectively (Figure $4 \mathrm{~b}$ ).

\section{Empirical Cumulative Probability Distributions for Prediction of Hyperketonemia During the First 8 Weeks in Lactation}

One-half of the cows showing hyperketonemia during the first $8 \mathrm{wk}$ in lactation $(\mathrm{n}=19)$ showed a milk fat C18:1 cis-9-to-C15:0 ratio of 45 or more in wk 2 with a false positive rate of $9.0 \%$. Only $15 \%$ of the hyperketonemia cows had a milk fat $\mathrm{C} 18: 1$ cis-9-to-C15:0 ratio of 30 or lower, whereas one-half of the nonhyperketonemia cows had these low ratios in milk fat ( $\beta_{1}$ value of logistic curve for nonhyperketonemia cases; Figure 5).

\section{DISCUSSION}

\section{Blood Plasma BHBA Threshold Values}

Duffield (2000) reported hyperketonemia prevalence of 8.9 to $34 \%$ for dairy cows in the first 8 wk of lactation. This is in agreement with the hyperketonemia incidence rate $(\mathrm{BHBA} \geq 1.2 \mathrm{mmol} / \mathrm{L}$ ) observed in the current study, which decreased as expected when progressing from wk 2 to 8 in lactation (26.9 to $6.5 \%$; Figure 1b). However, these incidence rates should be considered with caution given the weekly sampling protocol, which might have resulted in misclassifica- a)

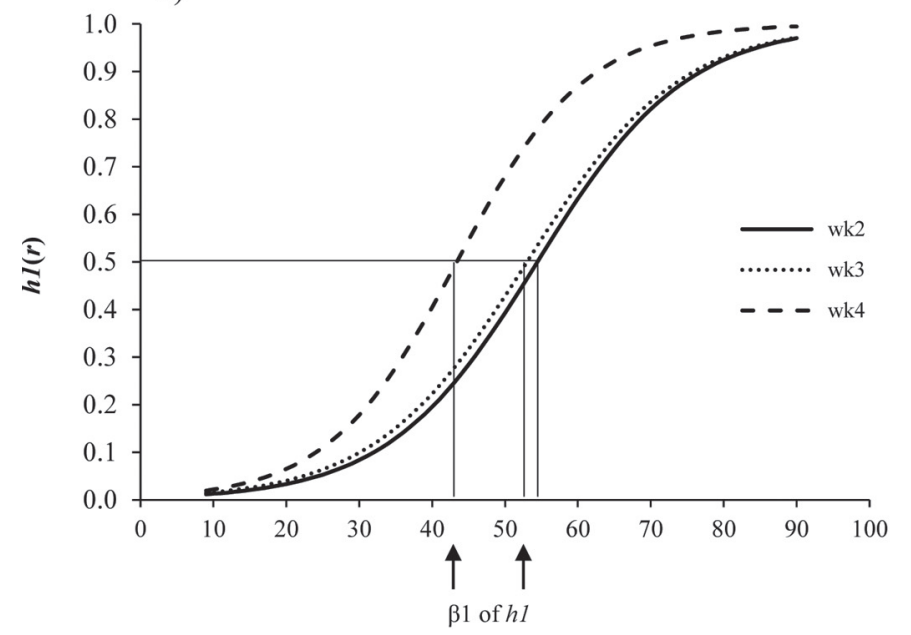

Milk fat ratio C18:1 cis-9-to-C15:0

b)

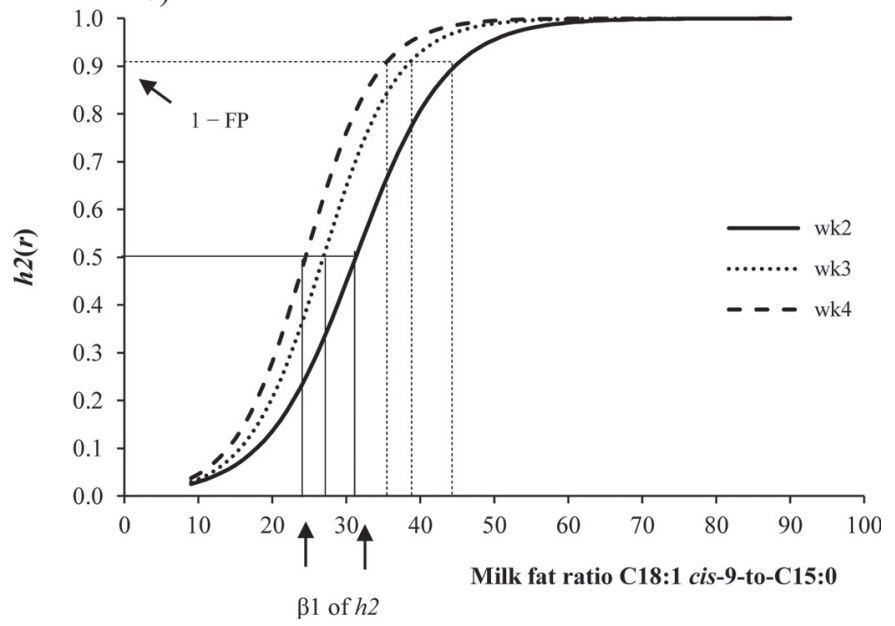

Figure 4. (a) A logistic curve, $h 1$, representing the cumulative probability distribution of hyperketonemia cases (BHBA $\geq 1.2$ $\mathrm{mmol} / \mathrm{L})$ showing a milk fat $\mathrm{C} 18: 1$ cis-9-to-C15:0 ratio $(R) \leq r$ to the total number of hyperketonemia cases of wk 2, 3, and 4 of lactation. The logistic curve is characterized by its slope $\left(\beta_{0}=0.10,0.10\right.$, and 0.11 for wk 2,3 , and 4 , respectively) and inflection point $\left(\beta_{1}=54.4\right.$, 53.0 and 43.4 for wk 2, 3, and 4, respectively). (b) A logistic curve, h2, representing the cumulative probability distribution of nonhyperketonemia cases (BHBA $<1.2 \mathrm{mmol} / \mathrm{L}$ ) showing a milk fat C18:1 cis9-to-C15:0 ratio $(R) \leq r$ to the total number of nonhyperketonemia cases of wk 2,3, and 4 of lactation. The logistic curve is characterized by its slope $\left(\beta_{0}=0.16,0.20\right.$, and 0.21 for wk 2,3 , and 4 , respectively) and inflection point $\left(\beta_{1}=31.3,26.9\right.$, and 24.5 for wk 2,3 , and 4 , respectively). Specificity of $90 \%$, which corresponds with a false positive (FP) rate of $10 \%$, was presented as $1-\mathrm{FP}$.

tion of some cows and, hence, underestimation of the incidence. A more appropriate sampling protocol for hyperketonemia should rely on a higher sampling frequency (e.g., 3 samplings/wk; McArt et al., 2013). Hyperketonemia is simply a condition referring to circulation of increased levels of ketone bodies, mainly 
BHBA. Consequently, blood BHBA has been used as an indicator for hyperketonemia with $1.2 \mathrm{mmol} / \mathrm{L}$ being used as threshold concentration (McArt et al., 2013). This BHBA threshold value is justified given negative effects on the cow's health and therefore negative effects on dairy farm economics when blood plasma BHBA exceeds this concentration. Blood BHBA $\geq 1.2$ $\mathrm{mmol} / \mathrm{L}$ from 2 to 15 DIM were associated with odds ratios of 1.5, 9.5, and 5.0 for metritis, clinical ketosis, and displaced abomasum, respectively (Suthar et al., 2013). Roberts et al. (2012) reported an increased risk of culling within the first 60 DIM associated with a blood BHBA threshold $\geq 1.2$ in wk 1 (odds ratio $=1.8$ ), and $\geq 1.6 \mathrm{mmol} / \mathrm{L}$ in wk 2 postpartum (odds ratio = 3.2). Moreover, Walsh et al. (2011) showed cows with serum BHBA in the first and second wk of lactation above 1.0 and $1.4 \mathrm{mmol} / \mathrm{L}$, respectively, showed a $20 \%$ lower success rate to conceive at first insemination. In addition, the odds of left-displaced abomasum were 8 times greater in cows with serum BHBA $\geq 1.2 \mathrm{mmol} / \mathrm{L}$ (LeBlanc et al., 2005). Ospina et al. (2010) reported lower BHBA thresholds (BHBA $\geq 10 \mathrm{mg} / \mathrm{dL}$, which is equivalent to $0.96 \mathrm{mmol} / \mathrm{L}$ ) to be associated with a $13 \%$ decrease in pregnancy rate.

\section{Milk FA or Their Ratios as Biomarkers of Hyperketonemia: Physiological Background}

A former preliminary study indicated elevated milk fat C18:1 cis-9 concentrations for hyperketonemia cases (Van Haelst et al., 2008). This is in accordance with the positive relation between milk fat C18:1 cis-9 and blood plasma NEFA concentration (Jorjong et al., 2014). Indeed, increased concentrations of NEFA in blood plasma result in major changes in FA supply to the mammary gland with $\mathrm{C} 16: 0, \mathrm{C} 18: 0$, and $\mathrm{C} 18: 1$ cis-9 being the predominant NEFA released (Hostens et al., 2012), with a further possible conversion of C18:0 to C18:1 cis-9 in the mammary gland through the action of $\Delta^{9}$-desaturase (Fievez et al., 2003). Although not in all cases [e.g., Ospina et al. (2013) found only $18 \%$ of the variability in BHBA concentration to be explained by NEFA during the first $2 \mathrm{wk}$ in lactation], BHBA and NEFA are often linked. Effective development of hyperketonemia and production in the liver of BHBA not only depend on the supply to the liver of NEFA, but also on the availability of glucose or glucogenic precursors (van Knegsel et al., 2007). Indeed, Itoh et al. (1998) noted that hyperketonemia is associated with increased concentrations of NEFA and decreased concentrations of glucose in blood. Hence, the ratio C18:1 cis-9-to-C15:0 has been included as an additional predictive variable in our study, given milk C15:0 originates from rumen propionate (Fievez et al., 2012). This ratio indeed has

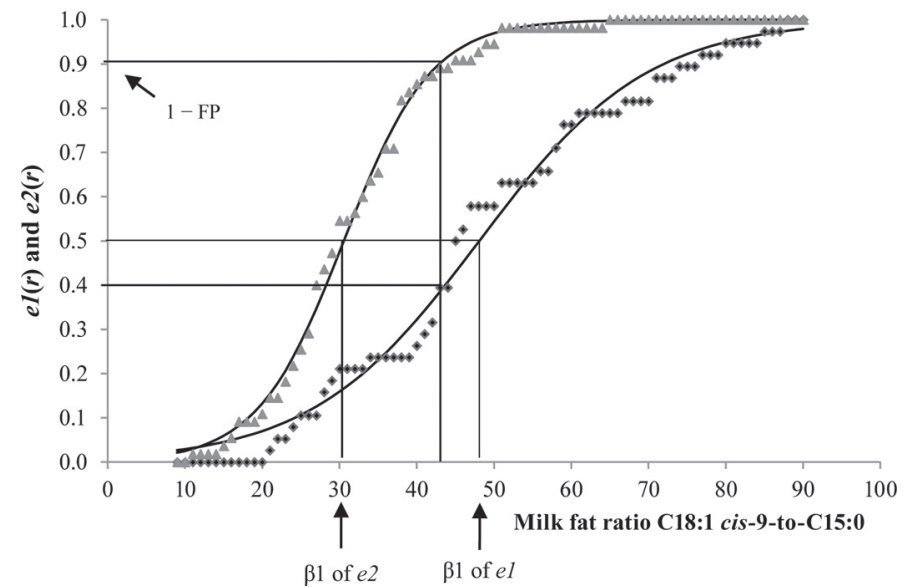

Figure 5. A logistic curve, e1, representing the cumulative probability distribution of cows suffering from hyperketonemia (BHBA $>1.2 \mathrm{mmol} / \mathrm{L}$ at any time in wk 2 to 8 in lactation) showing a milk fat C18:1 cis-9-to-C15:0 ratio in wk 2 of lactation $\left(R_{2}\right) \leq r$ (black diamonds) relative to the total number of cows suffering from hyperketonemia. The logistic curve is characterized by its slope $\left(\beta_{0}=\right.$ $0.09)$ and inflection point $\left(\beta_{1}=48.1\right)$. Similarly, cows not suffering from hyperketonemia (gray triangles) during the first 8 wk in lactation proportional to the total number of nonhyperketonemia cows (e2) were presented in relation to $R_{2} \leq r$, with $\beta_{0}$ and $\beta_{1}$ of 0.18 and 30.6, respectively. Specificity of $90 \%$, which corresponds with a false positive (FP) rate of $10 \%$, was presented as $1-\mathrm{FP}$.

been identified as the most discriminating variable. The progressive decrease in C18:1 cis-9-to-C15:0 ratio (Figures 1c, 4a, and $4 \mathrm{~b}$ ) is in line with the decreasing pattern of milk long-chain FA in early lactation and the increase observed for milk odd- and branched-chain fatty acids (OBCFA) with chain lengths of 14 and 15 carbon atoms (Craninx et al., 2008). Accordingly, information on this natural variation in milk FA concentrations should be incorporated in classification models based on these milk FA to improve their performance. Another milk FA ratio was included (i.e., anteiso C15:0to-anteiso $\mathrm{C} 17: 0)$. The rationale to include this ratio is based on FA elongase activity. Loor et al. (2007) indicated that mRNA expression encoding for elongase of family member 6 (ELOVL6) was downregulated in ketotic cows. Studies with cultured human intestinal cells revealed the potential of branched-chain FA to be elongated by the action of this enzyme (Ran-Ressler et al., 2010). Based on daily milk secretion of anteiso C17:0, which exceeded its daily duodenum flow, we suggested the possibility of elongation of this branched-chain FA from anteiso $\mathrm{C} 15: 0$ in animal tissues (Vlaeminck et al., 2015). Similarly, iso C15:0 elongation to iso C17:0 was suggested. However, the current gas chromatographic analysis did not allow for accurate determination of iso C17:0 due to co-elution with C16:1 cis-7. Downregulation of the activity of this elongase was hypothesized to result in an increased anteiso C15:0-to-anteiso C17:0 
Table 1. The average of milk fat and milk fat ratios for hyperketonemia and nonhyperketonemia cases, based on blood plasma BHBA ( $\geq 1.2$ and $<1.2 \mathrm{mmol} / \mathrm{L}$, respectively; SD in parentheses)

\begin{tabular}{lcccr}
\hline Status & $\mathrm{n}$ & $\begin{array}{c}\text { Milk fat C18:1 cis-9 } \\
(\mathrm{g} / 100 \mathrm{~g})\end{array}$ & $\begin{array}{c}\text { Milk fat ratio } \\
\text { C18:1 cis-9-to-C15:0 }\end{array}$ & $\begin{array}{c}\text { Milk fat ratio } \\
\text { anteiso C15:0-to-anteiso C17:0 }\end{array}$ \\
\hline Nonhyperketonemia & 299 & $20.6(4.06)$ & $25.6(10.89)$ & $0.88(0.172)$ \\
Hyperketonemia & 73 & $26.3(4.16)$ & $50.0(16.46)$ & $0.64(0.143)$ \\
$P$-value & & $<0.001$ & $<0.001$ & $<0.001$ \\
\hline
\end{tabular}

ratio in cows suffering from hyperketonemia. However, in the current study the anteiso C15:0-to-anteiso C17:0 ratio in milk of these cows was lower (Table 1). This might be due to a confounding effect related to more excessive fat mobilization in cows suffering from hyperketonemia. Indeed, released NEFA also might affect the milk fat anteiso $\mathrm{C} 15$ :0-to-anteiso $\mathrm{C} 17: 0$ ratio because adipose tissue is enriched in OBCFA of longer chain length. Craninx et al. (2008) indicated a ratio of C15 OBCFA to C17 OBCFA of 1:3 in adipose tissue of beef, whereas anteiso C15:0 and anteiso C17:0 in milk fat of nonhyperketonemia cows were presented in similar amounts. Accordingly, the greater amounts of anteiso C17:0 in milk fat of hyperketonemia cows most probably reflected a larger contribution from mobilized fat.

\section{Potential of Milk Fat Characteristics as Biomarkers of Hyperketonemia Compared with Other Cow-Side Tests}

Although the current experimental setup could have been improved, particularly with regard to sampling frequency, some first comparisons are made below to position the currently identified most powerful milk FA diagnostic within the range of cow-side tests that are available. A 10-fold cross validation for classification of hyperketonemia cases based on this milk FA ratio resulted in an average sensitivity of $38.4 \%$ and specificity of $95.0 \%$. Whereas specificity is highly acceptable, sensitivity is low. Other tests that rely on the detection of a single metabolite (i.e., most often ketone bodies) in blood, milk, or urine show variable performance, with the Precision Xtra for BHBA in whole blood being one of the most frequently performed tests, with sensitivity and specificity values of 88 and $96 \%$ at BHBA $\geq 1.2 \mathrm{mmol} / \mathrm{L}$ (Iwersen et al., 2009). Despite its high accuracy, this test has a major drawback of requiring invasive blood sampling. Urine collection is not invasive, and the performance of Ketostix (cutoff point "small") to detect acetoacetate showed sensitivity and specificity values of 78 and $96 \%$, respectively (Carrier et al., 2004). However, urine collection also has some limitations because it is labor intensive, particularly because urine production should be stimulated to allow pure sample collection with some cows failing to uri- nate. Additionally, these tests rely on visual interpretation of a color change, which may influence the result. Obviously, milk is the most convenient body fluid for collection, but milk tests are usually less sensitive than urine tests in monitoring hyperketonemia. Geishauser et al. (1998) evaluated the performance of Ketolac BHB strip test (threshold at $50 \mu \mathrm{mol}$ of BHBA/L of milk), which showed a sensitivity and specificity of 92 and $55 \%$, respectively, whereas a threshold at $100 \mu \mathrm{mol}$ of BHBA/L of milk indicated sensitivity and specificity values of 72 and $89 \%$, respectively. Four other tests (i.e., Ketostix strip, Bioketone powder, Ketocheck powder, and Utrecht powder) detecting acetoacetate in milk showed rather low sensitivities $(5,33,28$, and $43 \%$, respectively), whereas all tests were highly specific (specificity $>99 \%$ ). Alternative tests assessing the concentration of ketone bodies in milk are reported [e.g., KetoCheck Powder for detection acetoacetate (cutoff points: $\geq$ trace) with a sensitivity and specificity of 41 and $99 \%$, respectively]. The KetoTest strip for the detection of BHBA (threshold between 50 and $100 \mu \mathrm{mol}$ of BHBA/L of milk) showed sensitivity and specificity ranges between 73 to $88 \%$ and 90 to $96 \%$, respectively (Carrier et al., 2004). Duffield et al. (1997) found a milk protein to fat ratio of less than or equal to 0.75 to be another potential test for hyperketonemia, which yielded a sensitivity of $58 \%$ and specificity of $69 \%$. Although sensitivity and specificity are most commonly used to compare classification tests, it should be realized these values depend on class distribution. Because logistic regression analysis required independent input data and because milk fat C18:1 cis-9-to-C15:0 ratio changed with progress in lactation (Figures $4 \mathrm{a}$ and $4 \mathrm{~b}$ ), separate classification models needed to be developed for wk 2, 3, and 4, which resulted in a relatively low number of observations $(\mathrm{n}=93)$ for model cross-validation. Hence, model performance might improve when more independent data would become available. Furthermore, the former cow-side tests, like the milk fat $\mathrm{C} 18: 1$ cis-9-to-C15:0 ratio we proposed from the current research, all rely on the use of a single metabolite in blood, urine, or milk for the diagnosis of hyperketonemia. However, van der Drift et al. (2012) indicated classification of hyperketonemia to be considerably improved when combining Fourier transform 
infrared spectrophotometry predictions of milk acetone and milk BHBA with test day information. Due to limitations of the current experimental setup, it was not considered useful to further fine-tune and optimize the model using the current data set. Nevertheless, addition of test day information, for example, should be emphasized in the future when further developing a hyperketonemia diagnostic test based on the milk fat C18:1 cis-9-to-C15:0 ratio.

\section{CONCLUSIONS}

Milk fat C18:1 cis-9-to-C15:0 ratio shows potential for diagnosis of hyperketonemia in dairy cows. A ratio between 34 and 45 seems to be a valuable threshold in this respect, based on the current data set. Differentiation should be made in relation to the lactation week when milk sampling takes place.

\section{ACKNOWLEDGMENTS}

S. Jorjong acknowledges the support from the Royal Thai Government (Bangkok, Thailand) through a scholarship. The animal experiment was financed by the Dutch Dairy Board (Zoetermeer, the Netherlands), the Dutch Product Board Animal Feed (Zoetermeer, the Netherlands) and CRV (Arnhem, the Netherlands). Additionally, research was supported by an international coordinated action of the Fund for Scientific Research-Flanders (Brussels, Belgium).

\section{REFERENCES}

Ackman, R. G., and J. C. Sipos. 1964. Application of specific response factors in the gas chromatographic analysis of methyl esters of fatty acids with flame ionization detectors. J. Am. Oil Chem. Soc. $41: 377-378$

Carrier, J., S. Stewart, S. Godden, J. Fetrow, and P. Rapnicki. 2004. Evaluation and use of three cowside tests for detection of subclinical ketosis in early postpartum cows. J. Dairy Sci. 87:3725-3735.

Chapinal, N., M. E. Carson, S. J. LeBlanc, K. E. Leslie, S. Godden, M. Capel, J. E. P. Santos, M. W. Overton, and T. F. Duffield. 2012. The association of serum metabolites in the transition period with milk production and early-lactation reproductive performance. J. Dairy Sci. 95:1301-1309.

Chouinard, P. Y., V. Girard, and G. J. Brisson. 1997. Performance and profiles of milk fatty acids of cows fed full fat, heat-treated soybeans using various processing methods1. J. Dairy Sci. 80:334342.

Craninx, M., A. Steen, H. Van Laar, T. Van Nespen, J. Martín-Tereso, B. De Baets, and V. Fievez. 2008. Effect of lactation stage on the odd- and branched-chain milk fatty acids of dairy cattle under grazing and indoor conditions. J. Dairy Sci. 91:2662-2677.

Duffield, T. F. 2000. Subclinical ketosis in lactating dairy cattle. Vet. Clin. North Am. Food Anim. Pract. 16:231-253.

Duffield, T. F., D. F. Kelton, K. E. Leslie, K. D. Lissemore, and J. H. Lumsden. 1997. Use of test day milk fat and milk protein to detect subclinical ketosis in dairy cattle in Ontario. Can. Vet. J. $38: 713-718$.
Duffield, T. F., K. D. Lissemore, B. W. McBride, and K. E. Leslie. 2009. Impact of hyperketonemia in early lactation dairy cows on health and production. J. Dairy Sci. 92:571-580.

Fievez, V., E. Colman, J. M. Castro-Montoya, I. Stefanov, and B Vlaeminck. 2012. Milk odd- and branched-chain fatty acids as biomarkers of rumen function-An update. Anim. Feed Sci. Technol 172:51-65.

Fievez, V., B. Vlaeminck, M. S. Dhanoa, and R. J. Dewhurst. 2003 Use of principal component analysis to investigate the origin of heptadecenoic and conjugated linoleic acids in milk. J. Dairy Sci. 86:4047-4053.

Geishauser, T., K. E. Leslie, D. F. Kelton, and T. F. Duffield. 1998 Evaluation of five cowside tests for use with milk to detect subclinical ketosis in dairy cows. J. Dairy Sci. 81:438-443.

Graber, M., S. Kohler, A. Müller, K. Burgermeister, T. Kaufmann, R. M. Bruckmaier, and H. A. van Dorland. 2012. Identification of plasma and hepatic parameters related to metabolic robustness in dairy cows. J. Anim. Physiol. Anim. Nutr. (Berl.) 96:75-84.

Herdt, T. H. 2000. Ruminant adaptation to negative energy balance. Influences on the etiology of ketosis and fatty liver. Vet. Clin. North Am. Food Anim. Pract. 16:215-230.

Heuer, C., W. M. Van Straalen, Y. H. Schukken, A. Dirkzwager, and J. P. T. M. Noordhuizen. 2000. Prediction of energy balance in a high yielding dairy herd in early lactation: Model development and precision. Livest. Prod. Sci. 65:91-105.

Hostens, M., V. Fievez, J. L. M. R. Leroy, J. Van Ranst, B. Vlaeminck, and G. Opsomer. 2012. The fatty acid profile of subcutaneous and abdominal fat in dairy cows with left displacement of the abomasum. J. Dairy Sci. 95:3756-3765.

Itoh, N., M. Koiwa, A. Hatsugaya, H. Yokota, H. Taniyama, H. Okada, and K. Kudo. 1998. Comparative analysis of blood chemical values in primary ketosis and abomasal displacement in cows. J. Vet. Med. A 45:293-298.

Iwersen, M., U. Falkenberg, R. Voigtsberger, D. Forderung, and W. Heuwieser. 2009. Evaluation of an electronic cowside test to detect subclinical ketosis in dairy cows. J. Dairy Sci. 92:2618-2624.

Jorjong, S., A. T. M. van Knegsel, J. Verwaeren, M. V. Lahoz, R. M. Bruckmaier, B. De Baets, B. Kemp, and V. Fievez. 2014. Milk fatty acids as possible biomarkers to early diagnose elevated concentrations of blood plasma non-esterified fatty acids in dairy cows. J. Dairy Sci. 97:7054-7064.

LeBlanc, S. J., K. E. Leslie, and T. F. Duffield. 2005. Metabolic predictors of displaced abomasum in dairy cattle. J. Dairy Sci $88: 159-170$

Loor, J. J., R. E. Everts, M. Bionaz, H. M. Dann, D. E. Morin, R. Oliveira, S. L. Rodriguez-Zas, J. K. Drackley, and H. A. Lewin. 2007. Nutrition-induced ketosis alters metabolic and signaling gene networks in liver of periparturient dairy cows. Physiol. Genomics 32:105-116.

McArt, J. A. A., D. V. Nydam, and G. R. Oetzel. 2012. Epidemiology of subclinical ketosis in early lactation dairy cattle. J. Dairy Sci. 95:5056-5066

McArt, J. A. A., D. V. Nydam, and G. R. Oetzel. 2013. Dry period and parturient predictors of early lactation hyperketonemia in dairy cattle. J. Dairy Sci. 96:198-209.

Ospina, P. A., J. A. A. McArt, T. R. Overton, T. Stokol, and D. V. Nydam. 2013. Using nonesterified fatty acids and $\beta$-hydroxybutyrate concentrations during the transition period of herd-level monitoring of increased risk of disease and decreased reproductive and milking performance. Vet. Clin. North Am. Food Anim. Pract. $29: 387-412$.

Ospina, P. A., D. V. Nydam, T. Stokol, and T. R. Overton. 2010. Associations of elevated nonesterified fatty acids and $\beta$-hydroxybutyrate concentrations with early lactation reproductive performance and milk production in transition dairy cattle in the northeastern United States. J. Dairy Sci. 93:1596-1603.

Ran-Ressler, R. R., K. S. D. Kothapalli, R. P. Glahn, and J. T. Brenna. 2010. Branched chain fatty acids are taken up and metabolized by cultured human intestinal cells (Caco-2). FASEB J. 24:937.3. (Abstr.) 
Roberts, T., N. Chapinal, S. J. LeBlanc, D. F. Kelton, J. Dubuc, and T. F. Duffield. 2012. Metabolic parameters in transition cows as indicators for early-lactation culling risk. J. Dairy Sci. 95:30573063 .

Rukkwamsuk, T., T. Wensin, and M. J. H. Geelen. 1999. Effect of overfeeding during the dry period on the rate of esterification in adipose tissue of dairy cows during the periparturient period. J. Dairy Sci. 82:1164-1169.

Stefanov, I., V. Baeten, O. Abbas, E. Colman, B. Vlaeminck, B. De Baets, and V. Fievez. 2010. Analysis of milk odd-and branchedchain fatty acids using Fourier transform (FT)-Raman spectroscopy. J. Agric. Food Chem. 58:10804-10811.

Suthar, V. S., J. Canelas-Raposo, A. Deniz, and W. Heuwieser. 2013. Prevalence of subclinical ketosis and relationships with postpartum diseases in European dairy cows. J. Dairy Sci. 96:2925-2938.

Tamminga, S., W. M. Van Straalen, A. P. J. Subnel, R. G. M. Meijer, A. Steg, C. J. G. Wever, and M. C. Blok. 1994. The Dutch protein evaluation system: The DVE/OEB-system. Livest. Prod. Sci. 40:139-155.

van der Drift, S. G. A., R. Jorritsma, J. T. Schonewille, H. M. Knijn, and J. A. Stegeman. 2012. Routine detection of hyperketonemia in dairy cows using Fourier transform infrared spectroscopy analysis of $\beta$-hydroxybutyrate and acetone in milk in combination with test-day information. J. Dairy Sci. 95:4886-4898.

Van Es, A. J. H. 1975. Feed evaluation for dairy cows. Livest. Prod. Sci. 2:95-107.

Van Haelst, Y. N. T., A. Beeckman, A. T. M. Van Knegsel, and V. Fievez. 2008. Short Communication: Elevated concentrations of oleic acid and long-chain fatty acids in milk fat of multiparous subclinical ketotic cows. J. Dairy Sci. 91:4683-4686.

van Knegsel, A. T. M., G. J. Remmelink, S. Jorjong, V. Fievez, and B. Kemp. 2014. Effect of dry period length and dietary energy source on energy balance, milk yield, and milk composition of dairy cows. J. Dairy Sci. 97:1499-1512.

van Knegsel, A. T. M., H. van den Brand, J. Dijkstra, W. M. van Straalen, R. Jorritsma, S. Tamminga, and B. Kemp. 2007. Effect of glucogenic vs. lipogenic diets on energy balance, blood metabolites, and reproduction in primiparous and multiparous dairy cows in early lactation. J. Dairy Sci. 90:3397-3409.

Vlaeminck, B., R. Gervais, M. M. Rahman, F. Gadeyne, M. Gorniak, M. Doreau, and V. Fievez. 2015. Postruminal synthesis modifies the odd- and branched-chain fatty acid profile from the duodenum to milk. J. Dairy Sci. 98:4829-4840. http://dx.doi.org/10.3168/ jds.2014-9207.

Walsh, R. B., J. S. Walton, D. F. Kelton, S. J. LeBlanc, K. E. Leslie, and T. F. Duffield. 2007. The effect of subclinical ketosis in early lactation on reproductive performance of postpartum dairy cows. J. Dairy Sci. 90:2788-2796.

Walsh, S. W., E. J. Williams, and A. C. O. Evans. 2011. A review of the causes of poor fertility in high milk producing dairy cows. Anim. Reprod. Sci. 123:127-138.

Wolff, R. C., C. C. Bayard, and R. J. Fabien. 1995. Evaluation of sequential methods for the determination of butterfat fatty acid composition with emphasis on trans-18:1 acids. Application to the study of seasonal variations in French butters. J. Am. Oil Chem. Soc. $72: 1471-1483$ 